\title{
The management of acute spinal cord compression
}

\author{
Robin A Johnston
}

A wide variety of pathological lesions cause spinal cord compression. The clinical presentation may indicate the nature of the lesion although with modern imaging techniques the importance of making a clinical diagnosis of pathology has diminished. The important diagnostic aspect of acute spinal cord compression is that it should be recognised as early as possible and the patient referred with the urgency that each particular case merits. The over-riding reason for this is to enhance the chances of reversing the neurological damage by appropriate decompression surgery. Prognosis for recovery depends mainly on two factors: a) the severity of the neurological deficit and $b$ ) the duration of the deficit before decompression. There will be other factors taken into consideration when planning surgical management including general fitness, life expectancy, tumour pathology, and the extent of any metastatic spread. Successful spinal cord decompression means return of normal function in affected limbs and a stable, painless spine. Generally this means restoring independent walking although both patient and surgeon may have to settle for lesser degrees of functional recovery.

Spinal cord compression implies a "structural" lesion of the vertebral column compromising the spinal canal and producing a myelopathy. The signs and symptoms of spinal cord compression are those of motor and sensory deficit, but the common feature of "structural" lesions is pain. Spine pain or nerve root pain, occurring in the presence of myelopathic symptoms strongly implies a surgically remediable aetiology. The great majority of patients presenting with spinal cord compression reach hospital by referral through their general practitioner or through an Accident and Emergency Department and are usually admitted to general medical or surgical wards. In the early stages it may be difficult to detect abnormal neurological signs, especially if these are subtle and the pain component is large. For a variety of reasons, including late self-referral to any medical practitioner, delays can and do occur in the referral of such a patient to a specialist spinal unit. This was the subject of a candid and disturbing report by Maurice-Williams and Richardson in which they illustrate the diverse causes for delayed referral and the consequences of this. ${ }^{1}$ Any neurosurgeon or orthopaedic surgeon who carries out spinal decompression, will have experience of patients who are referred having been paraplegic for several days, well beyond the time of useful surgical treatment. Recognition of signs and symptoms of spinal cord compression may be difficult without a neuroscience environment and it is important that both neurosurgeons and neurologists take the trouble to facilitate referral from physicians and general surgeons at an early stage. This includes an ongoing educational element of which a most important aspect is to encourage colleagues to recognise the early signs of myelopathy. Easier access to spinal imaging should help.

\section{Trauma}

The most acute form of spinal cord compression is caused by trauma of which $50 \%$ occurs in the cervical spine and the great majority of the remainder in the thoracolumbar junction and lumbar spine. Patients are usually young males involved in road traffic accidents, falls and occasionally sport related activities. ${ }^{2}$ The forces involved can be resolved into flexion, extension, compression and rotation, although usually more than one is involved to produce the variety of different fracture patterns and subluxations seen in the cervical spine. In about $10 \%$ of cases, two non-contiguous levels of the cervical spine are damaged, separated by several normal segments. ${ }^{3}$

The management of acute spinal cord injury is the subject of many text books and publications and may be intimidating to those unfamiliar with this clinical problem. In fact the major components of management of spine trauma are analogous to the management of a fracture of a long bone. The management steps involved are recognition, immobilisation, investigation, reduction, fixation and rehabilitation. The cervical fracture should be recognised for what it is and in the great majority of cases the combination of neurological deficit, plus a painful and tender cervical region will indicate at least the possibility of cervical spine damage. Situations do occur where a patient is unable to provide a history because of decreased consciousness and in these it is better to make the assumption that cervical damage is present until proved otherwise. The cervical spine can be immobilised simply by holding the head firmly between two hands and maintaining the cervical spine in a neutral position until better facilities are available. Depending on the circumstances the patient may be fitted with an appropriate sized Philadelphia style collar, or be placed in cervical traction. The frequently used soft, spongy cervical collars
Neurological Sciences, UK.

R A Johnston
Department of Neurosurgery, Institute of 
are particularly ineffective in restricting cervical movements. One study indicates that this type of collar prevents only $25 \%$ of flexion and extension movements. A Philadelphia style collar rises to the occiput, spreads over the shoulders, rises over the chin and provides more effective immobilisation. Cervical tongs may be applied in the Casualty Department within a matter of seconds if the Gardner-Wells variety are used. These require only a little local anaesthetic and are placed $4 \mathrm{cms}$ above the external auditory meatus. They are simply hand-screwed through the anaesthetised scalp into the outer skull cortex to a pre-set tension. The doctor then has full control of the patient's cervical spine. Definitive investigations at an early stage must include a lateral plain $x$-ray of all cervical vertebrae. So many cases of missed fracture in the cervical spine are the result of inadequate $x$-rays which omit the lower vertebrae. Flexion/extension views can be particularly revealing. If carried out carefully the patient will come to no harm and the films may show abnormal movement. Cervical spine $x$-rays are difficult to read, especially for inexperienced junior staff and recourse should be had to experienced staff before management decisions are made on these patients. More definitive investigation is carried out by CT scanning, which almost always reveals more damage than was initially expected from plain $x$-rays. If C7 is unavailable through ordinary $x$-rays it is always accessible through CT scanning. MRI is beginning to be made available to patients with acute spinal injuries. ${ }^{4}$ It is particularly helpful in recognising damage to ligaments, discs and pre-vertebral tissues which have clearly altered signals with this form of scanning, but which may not be recognised using $x$-rays (fig 1).

Figure 1 MRI $(1 \cdot 5$ Tesla Seimens Magnetom, $T_{2}$ weighted scan) 24 hours after acute spinal trauma. The altered signal from the anterior longitudinal ligament opposite $C 2$ and C3 is clearly seen. This cervical spine has lost a substantial degree of stability.
At or about this stage in management, referral should be made to a specialised spinal unit, preferably an acute spinal cord injury unit. The newly opened National Spinal Cord Injuries Unit for Scotland now receives patients with spine trauma with and without cord injury within hours of injury in some cases. The pathophysiological consequences of acute spinal cord injury on the cardiovascular and respiratory symptoms and the intensive nursing requirements make early referral of these patients to an appropriate unit imperative. Spinal cord damage results in loss of sympathetic neural control causing hypotension and bradycardia. These are normal for the patient who has cord transection and should not be the subject of volume loading in misplaced attempts to restore "normal" blood pressure. Loss of intercostal innervation due to cranial cord trauma produces ventilatory insufficiency which is best managed in specialised units. ${ }^{5}$

Fractures, subluxations or dislocations require reduction into normal alignment. This may be relatively easily brought about using simple cervical traction. In the 1970s there was a vogue for using high loads of cervical traction, but this carries the risk of damage by traction on the spinal cord itself. Depending on the type and displacement of the injury, the position of the cervical spine can be altered using a rolled up sheet to exaggerate the lordotic curve. The vector of traction may be varied to enhance the likelihood of reducing the spine back to normal alignment. These techniques require frequent $x$ ray assessment and management experience. Should appropriate cervical traction be unsuccessful in reducing the fracture/dislocation the options are for manipulation under anaesthesia, which should only be carried out by experienced staff, or more commonly now, by open reduction and internal fixation. These latter decisions should be made by those experienced in dealing with spine trauma. Those patients who have vertebral damage but no spinal cord injury are to some extent vulnerable to secondary injury through inadvertent or accidental mishandling of the spine and in some ways have considerably more to lose than those patients who already have major spinal cord damage.

Fixation of the cervical spine may be carried out using external orthotic supports such as the halo fixator which is particularly useful for high cervical fractures. Even in this device a small degree of flexion and extension can still occur. Methods of internal fixation have evolved and improved, especially in recent years. In the cervical spine these involve plate and screw, wire or laminar clamp devices and do provide the patient with the ability to begin mobilisation and rehabilitation at an earlier stage. ${ }^{6}$ For thoracic and lumbar fractures the use of pedicle screw fixation reduces the number of vertebral levels permanently immobilised and allows peroperative fracture reduction and restoration of alignment in some cases. ${ }^{7}$ Malalignment of vertebrae is reduced using internal fixation, 
but longterm stability only comes through bony union. There is, and will continue to be, great debate amongst specialists in the management of patients with spinal cord injury concerning the merits and demerits of surgical intervention. What is clear is that in selected circumstances internal fixation and fusion does have a role to play and does impart advantages to the patient, his rehabilitation and his spine. What surgical intervention does not do, however, is improve neurological outcome. While there have been spurious and isolated reports of this there is no generally recognised association between surgical decompression and fixation, and neurological recovery in patients with acute spinal trauma.

The use of high doses of methylprednisolone has become standard practice in North America for patients with acute spinal trauma. This follows the results of studies which showed statistical improvement in limb function where these steroids were administered. ${ }^{8}$ This statistical improvement, however, may not be reflected in any significant functional or clinical gain by the patient. While the use of high dose methylprednisolone has, for reasons other than those which are entirely medical, gained widespread use in America this practice has not become established in the United Kingdom.

In patients who incur a severe head injury, the primary traumatic event is followed by a series of microvascular and biochemical changes which are recognised as the means by which secondary damage can compound the original injury. The same is true of spinal cord injury and it is possible that similar mechanisms are involved. The effect of the excitotoxic glutamate which is released following trauma to central neural tissue can be modified using $\mathrm{N}$-methyl $\mathrm{D}$-aspartate (NMDA) receptor blockade. Considerable attention currently focuses on biochemical methods of preventing or modifying the secondary damage produced following brain and spinal cord injury. ${ }^{9}$

\section{Inflammatory conditions}

The most common surgically relevant inflammatory spinal condition is rheumatoid disease which affects approximately $1 \%$ of the population in Western Europe. The cervical spine is involved in a substantial percentage of those patients who have rheumatoid disease with the incidence and severity increasing with the duration of the disease. The most common site of involvement is at the occipito-C1/C2 level, although all levels of the cervical spine may be involved. ${ }^{10}$

The fibrous inflammatory tissue mass is generally referred to as pannus although by strict definition pannus refers to the exudate overlying the synovial membrane. The fluctuating progress of the condition gradually destroys the joint tissues and articular surfaces which will lead to subluxation or even dislocation. This is frequently seen in the fingers and wrist joints of patients with rheumatoid disease, but does also occur at the occipito-C1/C2 level. The most common form of dislocation is anterior subluxation of $\mathrm{C} 1$ on $\mathrm{C} 2$ and this may be fixed or mobile depending on the activity of the inflammatory process. ${ }^{11-13}$ Eventually the condition will "burn out" and the joints may become ankylosed in an abnormal position. Loss of height of the lateral masses of Atlas will result in vertical translocation of the odontoid process and this occurs in about $10 \%$ of the affected population. Less frequently occurring abnormalities include posterior subluxation of $\mathrm{Cl}$ on $\mathrm{C} 2$ where the odontoid is totally eroded and the atlas can move posteriorly relative to the body of $\mathrm{C} 2$. Asymmetrical involvement of the lateral mass joints may lead to rotational deformities or lateral subluxations. ${ }^{14}$ The demonstration of these different types of atlanto-axial abnormalities has been enormously enhanced through the use of CT myelography including sagittal plane reconstruction, and with magnetic resonance scanning, both carried out with the patient flexing and extending her neck. ${ }^{15} 16$

With any subluxation in this region, or in the subaxial region, the spinal canal will be compromised and the patient may develop a myelopathy. One of the burning issues of epidemiological investigation into rheumatoid disease addresses the question of which patients with cervical spine involvement will go on to develop spinal cord compression. Unfortunately despite considerable effort there is no firm method of predicting which patients will deteriorate neurologically and which patients, with perhaps relatively severe radiological involvement, will never develop neurological signs or symptoms. Clinical markers have proved to be of little value, but more recent work involving measurement of cord diameter may prove to be of more value in predicting those patients who will require surgical intervention. ${ }^{17}$

Acute spinal cord compression is not common in rheumatoid disease although there are anecdotal cases of patients suddenly collapsing with paralysis and succumbing due to gross odontoid subluxation. Usually neurological symptoms develop over a period of weeks or even months, but a few patients do develop neurological signs and deteriorate with progressive myelopathy over a short period of days. They present with deterioration in gait quality and complain of sensory alteration or sensory loss, including loss of manual dexterity in the upper limbs. A clear clinical history is of paramount importance in confirming a myelopathy, since severe and widespread synovial joint involvement frequently precludes accurate assessment of deep tendon reflexes and muscle power. The patient will often be able to distinguish between new symptoms such as loss of strength or paraesthesia or significant gait deterioration and identify these separately from the symptoms of multiple joint involvement with which she is already very familiar. Isolated tendon reflexes may be elicited although plantar responses are almost never obtainable because of local joint involvement 
or previous surgery. Vertical subluxation of the odontoid process makes it possible that the patient will develop lower cranial nerve signs. In the past, speech difficulty, dysphonia and nystagmus have been attributed to high spinal cord or low medullary compression by pannus around the odontoid process. While this may be so in some cases, rheumatoid disease in the temporo-mandibular and cricoarytenoid joints may provide a more pragmatic cause. ${ }^{1819}$ In one of the largest series of rheumatoid patients that have been studied, Crockard found that nystagmus only occurred in those patients with pre-existing Chiari I malformation. ${ }^{17}$

When an acute cervical myelopathy is confirmed in a patient with rheumatoid disease the most likely cause will be anterior atlantoaxial subluxation. This can easily and rapidly be confirmed by a plain lateral $x$-ray of the cervical spine taken in flexion and extension. This will confirm only bone movement and position whereas soft tissue involvement will require the use of CT myelography or MRI. The purpose of management in this situation is to reduce the compression on the cervical cord and in the majority of cases this will be achieved by extending the upper cervical spine and bringing into more normal alignment the $\mathrm{C} 1$ and $\mathrm{C} 2$ vertebrae. However, it cannot be assumed that because vertebral alignment has been restored that spinal cord compression has been reduced. This will become apparent once scanning of the region has been carried out. Restoration of normal vertebral alignment is achieved using light cervical traction, preferably with titanium or carbon fibre tongs so there is no interference with subsequent scanning. The simplest and easiest type of cervical tong to apply is the Gardner-Wells version which requires only an injection of local anaesthesia into the scalp $4 \mathrm{cms}$ directly above the external auditory meatus. As the patient will most frequently be female and small, the weight required will rarely exceed 3 or 4 kilograms. Over the next 24 to 48 hours the patient will experience any neurological improvement that is likely to occur if reduction of cord compression has been achieved. It is at this time that the interest of a spine surgeon must be engaged and appropriate imaging of the region carried out. It is also important to recall that patients with multiple joint involvement due to rheumatoid disease do not tolerate prolonged cervical traction. If neurological improvement is not obvious within 72 hours it is probably unlikely to occur and traction should be discontinued. Once appropriate scanning has been carried out the surgical decision concerning continued immobilisation or interventional decompression, fixation and fusion will be made.

There are a variety of surgical procedures from which the surgeon may select those most appropriate to individual patients. The odontoid region can be approached directly by the transpharyngeal route in order to directly decompress the cervico-medullary region. It is recommended that this should be followed by a posterior stabilising operation which will generate fusion of $\mathrm{C} 1$ and $\mathrm{C} 2$ or occipital bone to $\mathrm{C} 2 .^{20-22}$ Subaxial cranial compression is less common than at $\mathrm{Cl}-2$ and usually also requires a combination of anterior and posterior surgery. At all levels the aim is to directly decompress the spinal cord, to restore vertebral alignment and to prevent further malalignment. For many patients a posterior C1-C2 fixation and fusion will be sufficient but in others the surgical procedure may be more complex. ${ }^{23-28}$

The postoperative mortality and morbidity rates are greatest in those patients who are not severely neurologically affected, that is, quadriparetic and unable to walk. The systemic effects of rhematoid disease, especially interstitial pulmonary involvement, may adversely affect postsurgical recovery. In those patients in whom the myelopathy is recognised and treated in the early stages the outlook for recovery is good and postoperative mortality is low. ${ }^{11}$

\section{Infective lesions}

Infections of the spine are uncommon; but can usefully be classified as either vertebral osteomyelitis or intraspinal infection. The former is the more common variety of infection and can lead to the latter whereas "pure" intraspinal infection comprises extradural, subdural or intramedullary abscess in descending order of frequency and without concomitant infection of the vertebral column. ${ }^{29}{ }^{30}$ Intraspinal infections occur at a frequency of approximately one per million per year in UK neurosurgical units and in the UK are predominantly caused by pyogenic organisms, usually Staphylococcus, whereas in Asia or Africa Mycobacterium tuberculosis is the common infecting organism. ${ }^{31}$

Extradural spinal abscess may be found anywhere within the spinal extradural space but this does not communicate with the intracranial extradural space because the two are separated at the foramen magnum where the outer, endosteal layer of the intracranial dura adheres to bone. The spinal dura is a single layer with the extradural space most prominent posteriorly and it is here that most extradural abscesses are found, the great majority being in the thoracic or lumbar spine. Cervical extradural abscess is uncommon and is usually associated with vertebral osteomyelitis. The abscess may extend over a few or many vertebral levels and it is well recognised that non-contiguous abscesses may occur. ${ }^{32} 33$

A spinal extradural abscess is a neurosurgical emergency and is one of the few instances where the history and clinical examination may provide an instant pathological diagnosis. The patient may, or may not, present with systemic signal illness, but as the abscess enlarges and compression of the spinal cord occurs then myelopathic symptoms gradually develop, usually over the course of a small number of days. ${ }^{34-36}$ The outstanding clinical feature is spinal pain and 
the marked local tenderness of the spine at the level of abscess formation. Tapping the spinous processes lightly with a tendon hammer may elicit this and indicate the pathological diagnosis. Several studies have reported the high frequency of misdiagnosis of this condition in its early stages. The complaint of spinal pain, particularly in younger patients and of thoracic pain in all patients should be regarded seriously enough to make a definitive pathological diagnosis rather than to assume the symptom is due to minor "mechanical dysfunction". By the time neurological symptoms are present, even in the absence of neurological signs, the probability of some form of surgically remediable structural spinal lesion increases considerably. Should the patient present with a paraplegia this should be regarded as a failure of diagnosis, as symptoms are frequently present for several days before this end stage.

The most valuable diagnostic exercise is high grade MRI scanning. ${ }^{37}$ This will confirm the diagnosis of extradural abscess, indicate its upper and lower limits, demonstrate whether or not there is an associated, and therefore probably primary osteomyelitis and in most cases differentiate between extradural abscess and subdural abscess. Myelography with CT scanning is the next best diagnostic investigation although the distinction between abscess, haematoma, or even in some cases metastatic tumour is not possible.

Investigations should be carried out without delay and the management of choice is by immediate surgical decompression. Since the abscesses are very commonly located in the posterior extradural space, albeit extending laterally on either side, this is one occasion where a decompressive laminectomy is the operation of choice. Attention should be paid to the upper and lower limits of the abscess although the laminectomy may not require to be taken to these extremes should the pus be of a liquid nature. On other occasions the laminectomy may need to be taken to the limits if the compressive material is semi-solid infected granulation tissue.

The results of surgery tell their own story and indicate that when patients are severely affected or paraplegic the likelihood of neurological recovery is poor. The mortality rate for this condition has diminished over the years with improving diagnosis, but is nevertheless substantial for a spinal condition and is variously reported at between $17 \%$ and $36 \% .{ }^{31} 38$

Vertebral osteomyelitis is a relatively uncommon condition, but familiar to spine surgeons in the United Kingdom. The commonest causes are staphylococci, streptococci, E coli and occasionally unusual organisms such as salmonella or brucella. For the most part the spinal cord is not affected and the problem is one of structural integrity of the vertebral column. ${ }^{39}$ However, both pyogenic and tuberculous osteomyelitis may lead to the formation of an extradural abscess lying anterior to the spinal cord, which may cause acute spinal cord compression in a fashion not dissimilar to a "pure" extradural abscess. The gradual progressive nature of bone infection will produce a more protracted preceding history, including spinal pain, aches, malaise, discomfort and system signs of infection culminating in an acute neurological deterioration.

Plain $x$-rays of the spine may give the diagnosis by revealing erosion and loss of height in contiguous vertebrae with destruction of the intervertebral disc. The coexistence of an extradural abscess is made by MRI or by CT myelography and is done as a matter of some urgency. It requires only a few millilitres of localised liquefied pus in the anterior cervical spinal canal to cause substantial tetraparesis, recovery from which is entirely possible with expeditious decompression. Scanning also reveals the extent of vertebral and paravertebral infection and can usually be distinguished from metastatic disease. ${ }^{40}$

For pyogenic osteomyelitis which predominates in the UK, direct ventral spinal canal decompression is often required. In the cervical spine this will involve an anterior cervical decompression procedure which can be carried out through an intervertebral disc space by a medial vertebrectomy. Division of the posterior longitudinal ligament usually results in the egress of a small volume of liquefied pus which is sometimes less than impressive considering the degree of paralysis which it has produced. In these acute situations the surgeon is best advised not to incorporate spinal reconstruction, but rather to return the patient to a period of external spinal stabilisation, usually by cervical traction, accompanied by appropriate intravenous antibiotic therapy. Once the infection has been treated in such a way for a period of several days, then more definitive means of stabilising the spine can be employed. In these situations where the pyogenic infection is under control, bone grafting almost always results in a solid fusion and in selected cases it is becoming accepted practice to use one or more of the forms of internal metal fixation while continuing antibiotic treatment.

In the thoracic and lumbar spine surgical decompression involves more difficult access, either by costo-transversectomy or posterior thoracotomy in the thoracic region and by the extra-peritoneal route in the lumbar region. In tuberculous osteomyelitis a limited postero-lateral decompression by costotransversectomy to release indolent purulent material is a satisfactory means of decompression with reconstruction and stabilising surgery reserved for later if necessary. ${ }^{41}$

\section{Degenerative pathology}

Degenerative change within the spine only causes acute spinal cord compression in a small group, but usually has a more prolonged course involving progressive neurological symptoms. ${ }^{42}$ Protrusion of intervertebral disc into the spinal canal, whether this be in the presence of existing osteophyte or not, can produce a rapidly developing myelopathy. 
Acute disc protrusions most commonly occur in the lumbar spine with $80 \%$ being located either at L4/5 or L5/S1. Central compression of the spinal theca at this level causes an acute cauda equina syndrome which is a spinal emergency. Isolated or "pure" cervical intervertebral disc protrusion is much less common than compression due to osteophyte formation although it is common to find a combination of both. "Pure" cervical disc prolapse can occur at any age and it may be that a pre-existing and relatively mild myelopathy rapidly becomes much worse because of protrusion of cervical disc a few millimetres further into the spinal canal. Acute myelopathy will present in older patients who have degenerative changes superimposed on a developmentally narrow cervical spinal canal ( $<10 \mathrm{~mm}$ AP diameter). In these patients the usual mechanism is violent hyperextension of the neck. ${ }^{43}$ "Pure" thoracic disc protrusion is uncommon and these patients present to neurosurgical units at a frequency of one per million per year. ${ }^{44}$ It is more common to find that the so called thoracic 'disc' is in fact a combination of osteophyte and calcified disc material, rather than degenerate nucleus pulposus which has prolapsed into the spinal canal.

In cases of acute disc protrusion, whichever the level, spinal pain usually accompanied by root pain is a common clinical symptom. The level of root pain provides a good indication of which intervertebral disc is the culprit. When the disc protrudes sufficiently into the spinal canal to cause spinal (or cauda equina) compression then neurological symptoms and signs accompany the pain. In the cervical and thoracic region these will lead to a myelopathy commensurate with the level of compression. Clinical determination of the sensory level gives a good indication of the level of thoracic disc prolapse. The distribution of pain, numbness, or "dropped" reflexes in the upper limbs provides a good clinical indicator to the level of cervical disc disease. When the patient produces symptoms which illustrate loss of manual dexterity it is often the case that compression is at the level of the $\mathrm{C} 3 / 4$ intervertebral disc. In the lumbar spine, compression of the cauda equina produces loss of sensation across the sacral dermatomes, either unilaterally or bilaterally, associated with root pain in both legs and with loss of bladder sphincter function. The clinical diagnosis of an acute disc prolapse in the cervical and lumbar spine is relatively straightforward, but misdiagnosis often occurs in the thoracic region. There may be a background history of thoracic spine pain and several studies have confirmed that probably because of the rarity of thoracic disc disease, other pathological diagnoses are given prior consideration..$^{44}$

The diagnosis is of disc prolapse confirmed radiologically by MRI of the appropriate spinal region. The alternative is CT myelography but with modern CT scanners contrast is usually not required to confirm lumbar disc prolapse although it is still required in the thoracic and cervical spine. ${ }^{45}$
The management of acute myelopathy or an acute cauda equina syndrome due to intervertebral disc prolapse involves urgent surgical decompression. In the lumbar spine this is carried out through a micro-discectomy approach and in the majority of cases this gives adequate access to the disc prolapse on both sides. Occasionally the access has to be increased by either a hemilaminectomy or on occasions by a full laminectomy. For those patients with coexisting lumbar canal stenosis it is recommended by some that a laminectomy is used to reduce the risk of a postsurgical cauda equina syndrome which occurs at a frequency of 1 in 500 lumbar disc operations. ${ }^{46}$

In the cervical spine disc prolapse causing myelopathy is removed through an anterior access route between the carotid sheath laterally and the pharynx/larynx medially. This is an approach to the subaxial spine and when the compression is due to disc prolapse alone a simple disc excision is satisfactory. This is carried out using an operating microscope with excision of the disc material and the cartilaginous end-plates down to the level of the posterior longitudinal ligament and laterally to the medial part of the unco-verterbral joints. It is necessary to open the posterior longitudinal ligament to directly visualise and explore the extradural space as disc material can find its way through the longitudinally orientated fibres of this ligament into the extradural space. It is not necessary to carry out a fusion procedure although this can be carried out either by the Smith-Robinson or Cloward technique if preferred. The use of a bone fusion does not confer additional neurological recovery, although it may be required (or preferred) if spinal stability is significantly degraded. Those patients in whom a fusion procedure is not carried out may be more susceptible to cervical pain for the first few weeks following the decompression and the use of a cervical collar is recommended. Laminectomy is not indicated for a patient with myelopathy due to acute cervical disc prolapse as this would involve unacceptable cord retraction to remove the disc.

For those patients who develop an acute myelopathy due to hyperextension forces superimposed on a narrow spinal canal there is little, if any, convincing evidence that surgical decompression improves neurological recovery. In those few patients who have a narrow cervical spinal canal and who develop an acute non-traumatic myelopathy, a laminectomy or a multiple level anterior decompression and fusion are the surgical alternatives although the presumed ischaemic pathogenesis does not incline to the favourable outcome associated with slowly developing spondylitic myelopathy. ${ }^{42}$

For a thoracic disc protrusion the surgical access must be either lateral or anterior or a combination of both. The approaches to the thoracic spinal canal are those which give access to the disc prolapse without requiring any retraction of the thoracic spinal cord and are such that the disc material may be 
removed in a direction away from the spinal theca. The recommended approaches are pediculectomy, costo-transversectomy or transthoracic partial vertebrectomy. ${ }^{44} 478$ A laminectomy is only indicated for thoracic disc prolapse if the disc material is entirely free and is located in a position lateral to the spinal cord. This does happen, but not commonly. A laminectomy for an anteriorly placed thoracic disc prolapse invites major neurological deterioration.

For patients who present with an acute disc prolapse causing cauda equina syndrome prognosis for recovery is based on the severity of the pre-decompression neurological deficit rather than the duration of neurological symptoms, although it is difficult to entirely separate these two components. ${ }^{49}$ The same is likely to apply to prognosis for recovery following cervical and thoracic disc induced myelopathy. Full recovery for expeditiously diagnosed and optimally managed patients is to be expected.

\section{Neoplastic cord compression}

By far the commonest type of neoplastic spinal cord compression is that caused by secondary tumour deposits and up to one third of patients with malignant disease have deposits in the spine. ${ }^{50} 51$ These are most commonly found in the vertebral body and pedicles with direct spread into the spinal canal. In about $5 \%$ of cases, metastatic tumour is confined to the spinal extradural space..$^{52}$ The usual and most common primary tumours are bronchus, breast, gastrointestinal tract, prostate, kidney, myeloma and lymphoma. Most secondary deposits are found in the thoracic spine and multiple lesions may be non-contiguous. The reasons for this are likely to be related to the venous drainage of affected primary organs being routed through the spinal extradural venous plexus. The relative size of the thoracic spine clearly also has an effect. Secondary deposits are less common in the lumbar and cervical spine. They are uncommon or even rare in the sacral spine.

As the tumour enlarges and encroaches on the spinal cord the signs and symptoms of myelopathy progressively develop. This is associated with spinal pain in over $90 \%$ of patients and in retrospect these patients are often found to have complained of pain in the affected region for many weeks before the development of clinical myelopathy. ${ }^{53}$ In the majority of cases the myelopathy progresses gradually, usually over a period of days or weeks. As the compression increases the ability of the spinal canal to accommodate the extra volume is exhausted and the rate of neurological deterioration increases rapidly. The typical patient will have complained of thoracic spinal pain for perhaps four or six weeks with gradual development of fatigue in the lower limbs followed by decreased gait quality and finally with rapid development of weakness and loss of sensation. The apparent acute presentation is therefore usually only the final stage of a more gradual process. ${ }^{54}$

Acute spinal cord compression due to secondary tumour does occur when the tumour enlarges very rapidly due to haemorrhage or where a vertebral body suddenly collapses because its structure has been extensively infiltrated by the neoplastic process.

The clinical features of presentation are not sufficiently characteristic to permit an accurate pathological diagnosis. Other causes of acute cord compression may present in a similar clinical fashion. The diagnosis must be confirmed by appropriate spinal imaging, initially by plain $x$-ray of the relevant spinal region although the whole spine needs to be managed as up to $17 \%$ of patients have multiple lesions. ${ }^{53}$ The typical features of metastatic involvement include loss of vertebral height, an irregular lucent appearance within the fine architecture of the bone, preservation of the intervertebral disc space and the possibility of multiple lesions. Spinal $x$-rays should be taken in combination with chest $x$-rays and the clinical examination, either or both of which may reveal evidence of a primary lesion. The optimal form of spinal imaging is by MR scan, or by CT myelography. ${ }^{55}$ All the relevant information can be obtained from MRI including the number of levels affected, the extent of any local extravertebral infiltration and soft tissue involvement. CT scanning gives a clear indication of the extent of bone involvement and makes surgical planning of the route of access and the achievable extent of excision more easy.

It may be that the pathological nature of the secondary tumour is circumstantially identified by locating the primary tumour. When no primary can be found it is important to identify the histopathological type of the tumour by biopsy. In the spine between T5 and L5 this can be achieved through percutaneous vertebral body biopsy carried out under biplanar image intensifier control..$^{56} \mathrm{An}$ alternative method is to use CT guided needle biopsy at almost any level, although this technique does not as readily provide samples of bone tissue, but rather of infiltrated soft tissue immediately adjacent to the vertebra. Either technique is safe in experienced hands and yields a high rate of positive diagnosis.

The subsequent management usually takes account of a number of factors, each with a varying influence on the management in different circumstances. ${ }^{57}$ The histopathology of the tumour must be taken into account with the overall tumour load, that is, the number of secondary deposits and the best estimate of the patient's life expectancy. The severity of the neurological deficit probably has the major influence on the neurological recovery following decompression surgery. The most severely affected patients and those who are paraplegic have the lowest chance of regaining the ability to walk independently. Lesser levels of recovery, which do not permit the patient to either transfer, stand or walk, are of little practical benefit although return of sensation is of great importance to someone who is confined to a wheelchair. 
The first surgical decision to be made is whether or not a surgical procedure is indicated. Surgery will provide the most rapid means of cord decompression, in contrast to radiotherapy which may take several days to have its optimum effect as a decompressing agent. Even patients with highly radiosensitive tumours such as myeloma or lymphoma occasionally require urgent surgical management where the compression is due to a collapsed vertebra rather than to tumour tissue surrounding the spinal cord.

The route of access should then be decided and at all spinal levels the surgeon has a choice of posterior, lateral or anterior routes. In general where the compression and major disease lies anterior to the spinal cord this should be the preferred route to decompression. This may be transoral, transcervical, transthoracic or retroperitoneal depending on the level of the spine affected. Lateral access can be achieved through a laminectomy extended laterally to include the pedicle and facet joint, a true costo-transversectomy or a lateral extra-cavity approach which is in effect an extended multiple level costotransversectomy. Where the spinal cord is primarily compressed posteriorly then a laminectomy still has a role to play. However, the days of simply carrying out a laminectomy for any form of neoplastic spinal cord compression are long since past. Studies from the late $70 \mathrm{~s}$ and early 80 s clearly showed how ineffective a laminectomy is in the presence of vertebral body disease. In this situation $20 \%$ of patients are made neurologically worse and a similar number are made unstable. The decompression process may entail removal of consider-

Figure 2 MRI (1.5 Tesla Seimens Magnetom) showing a cervico-thoracic extradural haematoma of spontaneous onset and unknown cause. The haematoma lies posterior to the spinal cord. able amounts of bone from the spine and require replacement using internal metallic fixation, bone graft, or in some cases methyl methacrylate in combination with metal fixation.

Surgical decision making in these situations is complex and preparing contingency plans for every clinical situation is not a practical proposition. The over-riding aims are to provide the most effective form of decompression of the spinal cord to leave the patient with a pain-free, stable spine, with return of function of the spinal cord. In some situations, such as a patient with widespread metastatic bronchogenic tumour, it is entirely inappropriate to carry out a transthoracic spinal decompression. In a patient who has multiple non-contiguous spinal lesions major surgery on any one of these is likely to be followed by further cord compression at a different level. In selected patients, however, even relatively major surgery to access and decompress the spinal cord is indicated before further treatment with radiotherapy or chemotherapy.

\section{Spinal cord compression by haematoma}

Extradural and subdural haematomas are common and well known conditions in cranial neurosurgery, but are distinctly uncommon in the spine. Subdural haematomas in particular are rare, with few cases being reported.58 Epidural haematomas, while uncommon, are a recognised cause of cord compression and about one third are associated with patients receiving anticoagulant therapy. Lumbar puncture in this group of patients may lead to the formation of a spinal epidural haematoma. A substantial proportion occur for no particular reason although in the literature they are associated with, or even causally related to, what might otherwise be described as minor traumas of everyday living. ${ }^{5960}$ It seems more likely that these are coincidental factors rather than causal. There is little evidence that arteriovenous abnormalities in the vertebra or other form of angiomatous malformation are causally related to more than a small number of spinal epidural haematomas. 6162

Their clinical presentation is similar to several other forms of structural spinal cord compression. Haematomas produce a combination of spinal pain and root pain, followed by a progressive myelopathy, whose features will depend on the level of compression. Occasionally the process develops over several days and there are documented cases in whom the myelopathy has developed over several weeks. ${ }^{63}$ The majority present relatively rapidly, within one or two days, and the diagnosis is confirmed by MRI or CT myelography. ${ }^{64}$ (fig 2). The appearances are those of an extradural compressive lesion although with MR scanning it is possible to distinguish haematoma from pus or extradural tumour in some cases. Treatment is by laminectomy at the level of compression. ${ }^{65}$ 
1 Maurice-Williams RS, Richardson PL. Spinal cord compression: delay in the diagnosis and referral of a com-
mon neurosurgical emergency. Br $¥$ Neurosurg 1988;2: mon ne.

2 Meyer PR. Acute injury retrieval and splinting techniques. In: Meyer PR, ed. Surgery of spine trauma. New York: Churchill Livingstone, 1989:1-21.

3 Vaccaro AR, An HS, Lin S, et al. Noncontiguous injuries of the spine. $\mathcal{F}$ Spinal Dis 1992;5:320-9.

4 Schaefer DM, Flanders AE, Osterholm JL, Northrup B. Prognostic significance of magnetic resonance imaging in the acute phase of cervical spine injury. 7 Neurosurg 1992;76:218-23.

5 Cane RD, Shapiro BA. Pulmonary effects of acute spinal cord injury: assessment and management. In: Meyer PR, ed. Surgery of spine trauma. New York: Churchill PR, ed. Surgery of spine trau

6 Aldrich EF, Weber PB, Crow WN. Halifax interlaminar clamp for posterior cervical fusion: a long term follow up review. $\mathcal{F}$ Neurosurg 1993;78:702-8.

7 McNamara MJ, Stephens GC, Spengler DM. Transpedicular short segment fusions for treatment of lumbar burst fractures. F Spinal Dis 1992;5:183-7.

8 Bracken MB, Shephard MJ, Collins WF, et al. Methylprednisolone or naloxone treatment after acute spinal cord injury: 1 year follow up data. Results of the
second national acute spinal cord injury study. $f$ Neurosurg 1992;76:23-31.

9 Tator CH, Fehlings MG. Review of the secondary injury theory of acute spinal cord trauma with emphasis on theory of acute spinal cord trauma with emphas

10 Johnston RA, Kelvin IG. Surgery of the rheumatoid cervical spine. Ann Rheum Dis 1990;49:845-50.

11 Santavirta S, Kottinen YT, Laasonen E, Honkanen V, Antti-Poika I, Kauppi $M$. Ten year results of operation for rheumatoid cervical spine disorders. $\mathcal{F}$ Bone foint Surg 1991;73-B:116-20

12 Mathews JA. Atlanto-axial subluxation in rheumatoid arthritis. Ann Rheum Dis 1974;33:526-31

13 Pellicci PM, Ranawat CS, Tsairis P, Bryan WJ.'A prospective study of the progression of rheumatoid arthritis of the cervical spine. $\mathcal{F}$ Bone foint Surg 1981; 63-A:342-50.

14 Santavirta S, Kankaanpaa U, Sandelin J, Laasonen E, Kottinen Y, Slatis P. Evaluation of patients with rheumatoid cervical spine. Scand $\mathcal{F}$ Rheumatol 1987;16: 9-16.

15 Bell GR, Stearns KL. Flexion-extension MRI of the upper rheumatoid cervical spine. Orthopaedics 1991;14: rheumatoid

16 Krodel A, Refior HJ, Westermann S. The importance of functional magnetic resonance imaging in the planning of stabilizing operations on the cervical spine in rheumatoid patients. Arch Orthop Trauma Surg 1989;109: 30-3.

17 Dvorak J, Grob D, Baumgartner H. Gschwent N, Graver W, Larsson S. Functional evaluation of the spinal cord by magnetic resonance imaging in patients with rheumatoid arthritis and instability of the upper cervical spine. Spine 1989;14:1057-64.

18 Rogers MA, Crockard HA. Nystagmus and joint position sensation; their importance in posterior occipito-cervical fusion in theumatoid arthritis. Presented in part, 19th Annual Meeting, Cervical Spine Research Society, Annual Meeting, Cervical Spine

19 Toolaner G. Cutaneous, sensory impairment in theumatoid atlanto-axial subluxation assessed quantitatively by electrical stimulation. Scand $\mathcal{F}$ Rheumatol 1987;16: 27-32.

20 Dickman CA, Locantro J, Fessler RG. The influence of transoral odontoid resection on stability of the craniovertebral junction. $\mathcal{F}$ Neurosurg 1992;77:525-30.

21 Crockard HA, Calder I, Ransford AO. One stage transoral decompression and posterior fixation in rheumatoid atlanto-axial subluxation. F Bone foint Surg 1990; 72-B:682-5.

22 Hadley MN, Spetzler RF, Sonntag, VKH. The transoral approach to the superior cervical spine. $f$ Neurosurg approach to the

23 Wertheim SB, Bohlman HH. Occipitocervical fusion. $\mathcal{F}$ Bone foint Surg 1987;69-A:833-6.

24 Ranawat CS, O'Leary P, Pellicci P, Tsairis P, Marchisello $P$, Dorr $L$. Cervical spine fusion in rheumatoid arthritis. f Bone foint Surg 1979;61-A:1003-10.

25 Chan CP, Ngian KS, Cohen L. Posterior upper cervical fusion in rheumatoid arthritis. Spine 1992;17:268-72.

26 Ferlic DC, Clayton, ML, Leidholt JD, Gamble WE. Surgical treatment of the symptomatic unstable cervical spine in rheumatoid arthritis. $\mathcal{F}$ Bone foint Surg 1975 ; 57-A:349-54.

27 Brattström H, Granholm L. Atlanto-axial fusion in rheumatoid arthritis. Acta Orthop Scand 1976;47: 619-28.

28 Grob D, Dvorak J, Gschwend N, Froehlich M. Posterior occipito-cervical fusion in rheumatoid arthritis. Arch Orthop Trauma Surg 1990;110:38-44.

29 Dutton JEM, Alexander GL. Intramedullary spinal abscess. I Neurol Neurosurg Psychiatry 1954;17:303-7.

30 Fraser RAR, Ratzan K, Wolpert SM, et al. Spinal subdural empyema. Arch Neurol 1973;28:235-8.

31 Johnston RA. Intraspinal infection. In: Findlay G, Owen
R, eds. Surgery of the spine. London: Blackwell, 1992: $621-8$.

32 Dandy WE. Abscesses and inflammatory tumors in the spinal epidural space (so called pachymeningitis externa). Arch Surg Chicago 1926;13:477-94.

33 Heusner AP. Non tuberculous spinal epidural infections. N Engl F Med 1948;239:845-54.

34 Statham P, Gentleman D. Importance of early diagnosis of acute spinal extradural abscess. F $R$ Soc Med 1989; 82:584-7.

35 Baker AS, Ojemann RG, Swartz MN, et al. Spinal epidural abscess. $N$ Engl f Med 1975;293:463-8.

36 Hakin RN, Burt AA, Cook JB. Acute epidural abscess. Paraplegia 1979;17:330-6.

37 Ross J. Inflammatory disease. In: Modic M, Masaryk T, Ross J, eds. Magnetic resonance imaging of the spine. Chicago: Year Book Medical, 1989:167-82.

38 Holme A, Dott NM. Spinal epidural abscess. BMF 1954;64:64-8.

39 Ho EKW, Leong JCY. Spinal osteomyelitis. In: Findlay G, Owen R, eds. Surgery of the spine. London: Blackwell Scientific, 1992:621-8.

40 Modic MT, Feiglin DH, Piraino DW, et al. Vertebral osteomyelitis; assessment using MR. Radiology 1985; 157:157-63.

41 Johnston RA, Hadley DM. Tuberculous infection of the thoracic spine. In: Tarlov EC, ed. Neurosurgical treatment of disorders of the thoracic spine. Illinois: American Association of Neurological Surgeons, 1991:95-109.

42 Ferguson RJL, Kaplan LR. Cervical spondylitic myelopathy. Neurol Clin 1985;3:373-82.

43 Epstein N, Epstein J. Benjamin V, et al. Traumatic myelopathy in patients with cervical spinal stenosis myelopathy in patients with cervical spinal stenosis

44 Russell $\mathrm{T}$. Thoracic intervertebral disc protrusion: experience of 67 cases and review of the literature. $\mathrm{Br} f$ Neurosurg 1989;3:153-60.

45 Wesolowski DP, Wang AM. Radiologic evaluation. In: Rothman RH, Simeone FA, eds. The Spine. Philadelphia: WB Saunders, 1992:570-6.

46 McLaren AC, Bailey SI. Cauda equina syndrome: a complication of lumbar discectomy. Clin Orthop 1986; 204:143-9.

47 Fidler MW, Goedhart ZD. Excision of prolapse of thoracic intervertebral disc. $f$ Bone $f t$ Surg 1984;66B: 518-22.

48 Russell $\mathrm{T}$. Thoracic intervertebral disc protrusion. In: Findlay G, Owen R, eds. Surgery of the spine. London: Findlay G, Owen R, eds. Surgery
Blackwell Scientific, 1992:813-20.

49 O'Laoire SA, Crockard HA, Thomas DG. Prognosis for sphincter recovery after operation for cauda equina compression owing to lumbar disc prolapse. $B M F 1981$; 282:1852-4

50 Schaberg J, Gainor B. A profile of metastatic carcinoma of the spine. Spine 1985;10:19-20.

51 Wong D, Fornasier V, MacNab I. Spinal metastases: The obvious, the occult and the imposters. Spine 1990; 15:1-4.

52 Constans J, de Divitus E, Donzelli R, et al. Spinal metastases with neurological manifestations: review of 600 cases. $\mathcal{F}$ Neurosurg 1983;59:111-18.

53 Gilbert R, Kim J, Posner J. Epidural spinal cord compression from metastatic tumor: diagnosis and treatment. Ann Neurol 1978;3:40-51.

54 Shapiro W, Posner J. Medical versus surgical treatment of metastatic spinal cord tumour. In: Thompson R, Green $\mathrm{J}$, eds. Controversies in Neurology. New York: Raven Press, 1983:57-65.

55 Godersky J, Smoker W, Knutzon R. Use of magnetic resonance imaging in the evaluation of metastatic spinal disease. Neurosurgery 1987;21:676-80.

56 Findlay G, Sandeman D, Buxton P. The role of needle biopsy in the management of malignant spinal compression. Br 7 Neurosurg 1988;2:479-84.

57 Findlay GFG. Metastatic spinal disease. In: Findlay G, Owen R, eds. Surgery of the spine. London: Blackwell Scientific, 1992:557-72.

58 Reinsel TE, Goldberg E, Granato DB, et al. Spinal subdural haematoma: A rare cause of recurrent postoperadive radiculopathy. $\mathcal{I}$ Spinal Dis 1993;6:62-7.

59 Cowie RA. Acute spinal haematoma. In: Findlay G, Owen R, eds. Surgery of the spine. London: Blackwell Scientific, 1992:621-8.

60 Bruyn GW, Bosma NJ. Spinal extradural haematoma. In: Vinken PJ, Bruyn GW, eds. Handbook of clinical neurology. Amsterdam: Elsevier, 1976;1-30.

61 Harris DJ, Fornasier VL, Livingstone KE. Haemangiopericytoma of the spinal canal. Report of three cases. $\mathcal{f}$ Neurosurg 1978;49:914-20.

62 Stuart Lee K, McWhorter JM, Angelo IV. Spinal epidural haematoma associated with Pagets disease. Surg Neurol 1988;30:131-4.

63 Boyd HR, Pear BL. Chronic spontaneous spinal epidural haematoma: report of two cases. $\mathcal{F}$ Neurosurg 1972;36: 239-42.

64 Larsson EM, Holtas S, Cronqvist S. Emergency magnetic resonance examination of patients with spinal cord resonance examination of patients with

65 Johnston RA, Bailey IC. Spinal extradural haematoma; report of two cases. Ulster Medical fournal 1983;52: report of 